REGARDS

SUR LEECONOMIE ALLEMANDE

BULLETIN ECONOMIQUE DU CRAC

\section{Regards sur l'économie allemande}

Bulletin économique du CIRAC

$84 \mid 2007$

Varia

\title{
Etudes PIRLS et PISA 2006 : l'Allemagne en progrès
}

\section{Werner Zettelmeier}

\section{CpenEdition}

\section{Journals}

Édition électronique

URL : http://journals.openedition.org/rea/569

DOI : $10.4000 /$ rea.569

ISBN : 978-2-8218-0864-5

ISSN : 1965-0787

Éditeur

CIRAC

Édition imprimée

Date de publication : 1 décembre 2007

Pagination : 35-36

ISSN : 1156-8992

Référence électronique

Werner Zettelmeier, «Etudes PIRLS et PISA 2006 : I'Allemagne en progrès », Regards sur l'économie allemande [En ligne], 84 I décembre 2007, document 2, mis en ligne le 01 décembre 2009, consulté le 15 septembre 2020. URL : http://journals.openedition.org/rea/569

Ce document a été généré automatiquement le 15 septembre 2020

(C) CIRAC 


\title{
Etudes PIRLS et PISA 2006 : l'Allemagne en progrès
}

\author{
Werner Zettelmeier
}

1 Les résultats de la nouvelle étude PISA que l'OCDE vient de publier donnent quelques motifs de satisfaction aux responsables du système éducatif allemand, même si des progrès restent à faire si l'Allemagne veut rejoindre la Finlande, toujours en tête du classement comme lors de la première étude publiée en 2001.

\section{PISA : I'Allemagne au $8^{\mathrm{e}}$ rang en sciences}

Dans le cadre de la version 2006 de l'étude, l'accent a été mis sur l'évaluation des compétences en sciences. Ainsi, 400000 élèves de 15 ans représentant 57 pays, dont 30 pays de l'OCDE, ont été évalués. C'est surtout en sciences que les élèves allemands, sans différences significatives entre filles et garçons, font état d'une nette progression par rapport aux résultats obtenus dans les études précédentes (2000 et 2003). En effet, parmi les pays de l'OCDE, l'Allemagne occupe maintenant le $8^{\mathrm{e}}$ rang, alors qu'elle se situait en bas du classement en $2000\left(20^{\mathrm{e}}\right)$ et en $2003\left(15^{\mathrm{e}}\right)$. Cette progression concerne tous les niveaux d'élèves, des meilleurs aux plus faibles, même si les écarts entre les deux groupes restent particulièrement élevés. Les résultats confirment la persistance d'un lien, certes moins fort par rapport aux études précédentes, mais toujours significatif, entre performances scolaires et origine sociale de l'élève. Les écarts constatés entre les résultats scolaires des jeunes issus de l'immigration et ceux des jeunes Allemands 'de souche' sont particulièrement importants, et cette disparité reste caractéristique du cas allemand. 


\section{Etude PIRLS sur les compétences en lecture dans le primaire : I'Allemagne $11^{\mathrm{e}}$, la France $26^{\mathrm{e}}$}

3 Des progrès restent à faire dans la maîtrise des compétences en lecture et en mathématiques, où les performances des élèves allemands restent moyennes, même si elles se sont légèrement améliorées, faisant passer le pays de la $20^{\mathrm{e}}$ (lecture) et $21^{\mathrm{e}}$ (mathématiques) place en 2000 à la $14^{\mathrm{e}}$ parmi les pays de l'OCDE en 2006. Il est intéressant d'observer que dans ces deux domaines les différences des compétences entre filles et garçons sont significatives. Si les garçons sont meilleurs en mathématiques, les filles sont meilleures en lecture. Leur progression depuis 2003 est très nette et semble confirmer les résultats plutôt satisfaisants de l'étude internationale PIRLS, qui ont été publiés fin novembre. Cette étude porte sur les compétences en lecture des élèves du primaire ( $4^{\mathrm{e}}$ classe en Allemagne, CM1 en France). L'Allemagne se situe dans le quart supérieur ( $11^{\mathrm{e}}$ rang sur 45 Etats et régions participants), la France, quant à elle arrive en $26^{\mathrm{e}}$ position.

\section{Le fruit des réformes engagées après le « choc » de PISA}

Par rapport à l'étude PISA de 2000 dont les résultats médiocres affichés par les élèves de l'époque avaient provoqué un véritable « choc » dans l'opinion publique allemande, les responsables politiques expliquent l'amélioration des performances des élèves allemands comme un premier effet des réformes entreprises dans l'enseignement scolaire et pré-scolaire (voir REA 66/04). En effet, le choc de PISA 2000 peut être considéré comme salutaire en ce sens qu'il a provoqué une vaste prise de conscience au niveau politique de la nécessité des réformes que les spécialistes sur le terrain appelaient de leurs vœux depuis longtemps. Ces réformes portent à la fois sur les conditions matérielles dans lesquelles les élèves doivent travailler au sein des établissements scolaires (par exemple la multiplication d'établissements fonctionnant toute la journée pour permettre un meilleur encadrement des jeunes), mais plus encore sur les pratiques pédagogiques au sein de la classe par une meilleure formation initiale et continue des enseignants, par un meilleur suivi individuel de l'élève et par une plus grande autonomie administrative et pédagogique de chaque établissement. L'objectif global est d'atteindre une meilleure lisibilité des résultats scolaires et d'axer le pilotage du système dans son ensemble sur les résultats obtenus, ceux-ci devant être comparables tant au niveau national qu'international.

De ce point de vue, l'évolution du système éducatif allemand depuis quelques années peut apporter un éclairage intéressant au débat français sur l'école. Alors que l'opinion publique française avait peu commenté les résultats obtenus par les élèves français dans le cadre de l'étude PISA de 2001, les résultats de 2006 pourraient changer la donne. En effet, les résultats de 2006 sont moins bons que ceux de 2001 et 2003 pour les élèves français. Pour les sciences, la France passe du $10^{\mathrm{e}}$ au $19^{\mathrm{e}}$ rang, en lecture, du $14^{\mathrm{e}}$ au $17^{\mathrm{e}}$ rang et, en mathématiques, du $13^{\mathrm{e}}$ au $17^{\mathrm{e}}$ rang. Ce recul devrait inciter la France, à l'image de ce qui s'est passé en Allemagne, à s'interroger sur les raisons des mauvaises performances de son système éducatif et pourrait l'aider à surmonter les blocages, 
notamment corporatistes, contre des réformes indispensables pour reconquérir sa compétitivité dans l'économie du savoir.

INDEX

Mots-clés : éducation, enseignement, étude, lecture, sciences 